\title{
Técnicas analíticas contemporáneas para la identificación de residuos de sulfonamidas, quinolonas y cloranfenicol
}

\author{
Y. Verónica Talero-Pérez ${ }^{1 凶}$, Oscar Julio Medina ${ }^{1}$, Wilson Rozo-Núñez ${ }^{2}$
}

\section{Contemporary analytical techniques to identify residues of sulfonamides, quinolones and chloramphenicol}

\begin{abstract}
The excessive use of drugs in the veterinary industry generates bioaccumulation in animal organs, tissues, muscles and fat. Depending on the concentration, these residues can reach man via the food chain. Food safety comprehends the use of these drugs and their residues such as sulfonamides, chloramphenicol and quinolones, which have been found in different slaughter animals. Some countries have limited regulations to control this issue. The implementation of standards set by the European Union is essential to monitor and control this problem at a national level. In this review, we use analytical techniques to identify the residues produced by these drugs, focusing on recently developed technologies that are essential tools to control this problem. Liquid chromatography combined with mass spectrometry and its various interface systems is the most recommended technology to detect residues in various food matrices.
\end{abstract}

Keywords: Bioaccumulation; growth promoters; drugs; residue control; food safety; liquid chromatography; mass spectrometry.

Edited by Alberto Acosta

1. Grupo de investigación en Química y Tecnología de Alimentos (GIQTA)

2. Laboratorio de Síntesis Orgánica, Grupo de Investigación en Química-Física Molecular y Modelamiento Computacional (Quimol), Escuela de Ciencias Químicas, Facultad de Ciencias, Universidad Pedagógica y Tecnológica de Colombia, (UPTC) Tunja- BoyacáColombia.

Received: 9-04-2013 Accepted: 23-11-2013 Published on line: 21-12-2013

Citation: Talero-Pérez YV, Medina OJ, Rozo-Núñez W (2014) Técnicas analíticas contemporáneas para la identificación de residuos de sulfonamidas, quinolonas y cloranfenicol. Universitas Scientiarum 19(1): 11-28 doi: 10.11144/Javeriana.SC19-1.taci

Funding: Dirección de Investigaciones de la Universidad Pedagógica y Tecnológica de Colombia.

Electronic supplementary material: N/A

SICI: 2027-1352(201401/03)19:1<011:TACPLIDRDSQYC>2.0.TS;2-O

\section{Introducción}

Los antibióticos son sustancias químicas producidas por diferentes especies de microorganismos que suprimen el crecimiento de otros microorganismos y pueden eventualmente destruirlos (P.T.I.NS. 1990). El anuncio del primer antibiótico sulfamídico en 1935 inició la era moderna de la terapéutica antimicrobiana, caracterizada por una enorme disminución de la morbilidad y de la mortalidad para muchas enfermedades infecciosas (Gimeno 2001, Toldrá \& Reig 2006). El impacto de este tipo de sustancias sobre factores médicos, veterinarios, de sanidad pública y económica relacionados con los estados patológicos, no tiene paralelo en la historia de la terapéutica medicamentosa. Por consiguiente, los antibióticos constituyen uno de los agentes 
farmacológicos empleados de forma reiterativa, y en algunos casos usados sin ningún control, como suplemento alimenticio o para tratar enfermedades en animales y favorecer su crecimiento, siendo administrados en numerosas ocasiones de forma insensata y en dosis inadecuadas. En consecuencia, el empleo indiscriminado de estas sustancias puede producir alteraciones como: reacciones alérgicas, carcinogenicidad, mutagenicidad, teratogenicidad, anemia aplástica, súper-infecciones y retrasos en la identificación del germen causal. En efecto, el uso irresponsable de los medicamentos facilita la liberación de fragmentos de ácido desoxirribonucleico (ADN) que ayudan a las bacterias a aumentar la resistencia a ellos y colonizar ambientes en los que normalmente no podrían sobrevivir. Esta problemática es uno de los factores que incide en la aparición de gérmenes antibiótico-resistentes, creando la necesidad cada vez mayor de nuevos fármacos (Doyle 2006, Márquez 2008, Lozano \& Arias 2008, Reig \& Toldrá 2008, Le Bizec et al. 2009, Reig 2010). Por ello se hace necesaria la existencia de una regulación y vigilancia estricta en el manejo de residuos que pudieran contener estos genes que hacen a las bacterias más resistentes.

Generalidades: Los antibióticos se incluyen dentro del amplio grupo de compuestos que forman parte de la composición de un pienso animal, que pueden actuar con dos fines claramente diferenciados:

1. Como terapéuticos y profilácticos, debido a que los piensos constituyen una de las vías de administración más usadas para suministrar los fármacos en el sector veterinario. Los antibióticos se incorporan a los piensos en forma de premezclas medicamentosas (sólidas o líquidas) a concentraciones relativamente elevadas.

2. Como promotores de crecimiento, en países donde no están taxativamente prohibidos, cuya incorporación favorece el control de la flora bacteriana del animal, que se traduce en un mayor aprovechamiento de los nutrientes y un aumento considerable de peso. En este caso, se incorpora al pienso en forma de aditivo y en concentraciones sub-terapéuticas (Cancho et al. 2000, Márquez 2008, Reig \& Toldrá 2008).
La administración de antibióticos a animales de abasto destinados al consumo humano, facilita el control de enfermedades infecciosas y permite una mejora de la producción al promover el crecimiento. Sin embargo, dependiendo del tiempo trascurrido entre la administración de un antibiótico y el sacrificio (tiempo de espera) pueden quedar residuos de estas sustancias en los mismos tejidos utilizados como alimento. Estos residuos se han encontrado a través del tiempo en muestras de pienso, pelo, orina, músculos, hígado, riñones, grasa, leche, miel y huevos, especialmente en animales de granja y se han encontrado también en productos pesqueros (Huetos 2004, Stolker \& Brinkman 2005, Gentili et al. 2005, Gratacós 2007, Consentino 2009, Reig 2010). Estos compuestos y sus metabolitos son eliminados a través de las heces u orina de los animales tratados, dispersándose en el medio ambiente (Gratacós 2007).

Por consiguiente, resulta necesario establecer límites máximos residuales (LMR) para aquellas sustancias farmacológicas activas que se utilizan en los medicamentos veterinarios. El LMR se define como aquella concentración aceptable de una sustancia en los tejidos comestibles de un animal (músculos, hígado, riñones, grasa, leche, miel y huevos) y que al ser ingerida por el ser humano no constituye ningún riesgo para su salud; por ello se fijan LMR para cada especie animal y para cada tejido (Poucke et al. 2003, Stolker \& Brinkman 2005, Márquez 2008). Debido a que el riesgo para los consumidores de productos alimenticios de origen animal proviene de los residuos de los medicamentos, que comprenden tanto el compuesto original como sus productos de degradación, para la Unión Europea la evaluación de la seguridad de los residuos se realiza de acuerdo con el Reglamento (CEE) no 2377/90, del Consejo de Europa, siguiendo un proceso conocido como análisis de riesgos, que abarca tres fases que discurren de forma secuencial (CVMP 2001). La primera, conocida como evaluación del riesgo, es de carácter eminentemente científico, la cual se divide, a su vez, en cuatro etapas interrelacionadas: identificación del peligro, caracterización del peligro, evaluación de la exposición y caracterización del riesgo. Las dos primeras corresponden al proceso de identificación de los residuos potencialmente peligrosos presentes en los alimentos y a la evaluación cualitativa y cuantitativa de sus efectos. Esta evaluación se basa en la determinación de un nivel sin efecto para cada 
sustancia activa ("no-observed-effectlevel"; NOEL) y en el establecimiento de factores de seguridad para el cálculo de la ingesta diaria aceptable (IDA), que es la cantidad de residuos que puede ser consumida diariamente por el hombre durante toda su vida sin riesgo apreciable para la salud. Paralelamente, se lleva a cabo la evaluación de la exposición mediante la que se estima cuantitativamente la ingesta de los residuos en función de una dieta estándar que incluye la totalidad de los alimentos en los que pueda aparecer el residuo de interés. La caracterización del riesgo consiste en la estimación del riesgo para el consumidor teniendo en cuenta su probabilidad de materializarse, establecida durante el proceso de evaluación de la exposición, y la gravedad del mismo, determinada en la fase de caracterización del peligro. Como resultado de esta ponderación se decide la conveniencia de establecer unos límites máximos de residuos (LMRs), que indican la concentración máxima de residuos que puede aceptarse en un alimento como resultado del uso de un medicamento veterinario en animales destinados al consumo humano.

La segunda fase del análisis de riegos consiste en la gestión del riesgo, en virtud de la cual se adoptan medidas necesarias para la prevención y el control del riesgo de los residuos, la fijación de LMRs para cada sustancia farmacológicamente activa formulada como medicamento, la determinación del tiempo de espera que debe transcurrir entre la última administración del medicamento y el sacrificio del animal o la obtención de sus productos de forma que no contengan residuos en cantidades superiores a los LMRs fijados, el desarrollo y validación de métodos analíticos de los residuos y, finalmente, la implementación de planes de investigación y control de los residuos tanto en los animales vivos como en sus productos.

El análisis de riesgos culmina en la fase de comunicación del riesgo, consistente en el intercambio de información sobre el riesgo de los residuos entre todos los agentes involucrados: administraciones, consumidores, industria, etc. La información puede aparecer recogida en informes de expertos, informes sobre el resultado de los planes de control de residuos, alertas alimentarias, disposiciones legales, y se vehicula a través de los medios de comunicación de masas, páginas web institucionales y redes especializadas en seguridad alimentaria (Montalvo et al. 2004). Con respecto a estos LMRs no hay claridad con los riesgos asociados por la ingesta diaria de un mismo residuo de antibiótico y la sumatoria de esté, en un determinado tiempo, para una población y dieta específica. En general, se conoce que puede acarrear a la larga, efectos acumulativos o alteraciones subclínicas que se traducen en toxicidades crónicas o subcrónicas según los casos (Huetos 2004).

Además, de la UE y la FDA, a nivel internacional, el Codex alimentarius también ha establecido los LMR. El trabajo desarrollado por la comisión del Codex alimentarius es reconocido en el mundo entero por su invaluable aporte a la protección del consumidor y al comercio internacional. En síntesis el Codex alimentarius junto con la FAO/OMS se ocupan de la ejecución del programa sobre normas alimentarias, dentro del cual se establecen los LMR en los alimentos de tal forma que se garanticen la protección de la salud de los consumidores. Dado que en Colombia aún no se han definido dichos límites, es de resaltar que ya existe un proyecto de resolución; por lo tanto, para este tipo de regulación se hace necesario tomar como referencia la información de la FDA y la Unión Europea que han definido los LMRs para diferentes sustancias entre las cuales se encuentran las sulfonamidas, cloranfenicol y quinolonas, en diferentes matrices alimentarias (Tabla 1).

$\mathrm{Al}$ respecto, el cloranfenicol es una sustancia prohibida en la UE y no tiene LMR, pero si tiene asignado un MRLP (minimun required performance limit; por sus siglas en inglés) que es el límite mínimo de funcionamiento exigido, dispuesto en la decisión 2002/657/CE de la Comisión Europea, en donde se describe el nivel de concentración al cual una sustancia no autorizada ha sido medida. Esta situación pone de manifiesto el reto que enfrenta Colombia en materia de inocuidad de alimentos y de residualidad de medicamentos presentes en productos de consumo masivo; dada la creciente liberalización del comercio de productos agrícolas y alimentos, y en particular, con relación al Tratado de Libre Comercio con los Estados Unidos de América y otros países. De esta manera, se hace necesario disponer de protocolos de diagnóstico suficientes que permitan definir la problemática, con el fin de sentar las bases para su vigilancia y control. Para ello Colombia debe definir las sustancias que pueden ser usadas y los límites permitidos, y a futuro su eliminación completa para la producción animal. 
Tabla 1. LMRs para diferentes sustancias sulfonamidas, cloranfenicol y quinolonas, en diferentes matrices alimentarias. Niveles de tolerancia de antibióticos en comidas estipulados por la Unión Europea (EU) y la administración de drogas y alimentos de USA (FDA)

\begin{tabular}{|c|c|c|c|c|c|c|c|c|c|c|c|c|c|c|}
\hline & \multicolumn{14}{|c|}{ Límite máximo residual LMR (ppb) $\mu \mathrm{g} / \mathrm{kg}$} \\
\hline & \multicolumn{2}{|c|}{ Leche } & \multicolumn{2}{|c|}{ Huevos } & \multicolumn{2}{|c|}{ Músculo } & \multicolumn{2}{|c|}{ Hígado } & \multicolumn{2}{|c|}{ Riñón } & \multicolumn{2}{|c|}{ Grasa } & \multicolumn{2}{|c|}{ Pescado } \\
\hline & EU & FDA & EU & FDA & EU & FDA & EU & FDA & EU & FDA & EU & FDA & EU & FDA \\
\hline \multicolumn{15}{|l|}{ Tetraciclinas } \\
\hline Tetraciclina & 100 & 80 & 200 & & 100 & 2000 & 300 & 6000 & 600 & 12000 & & 12000 & & \\
\hline Oxitetraciclina & 100 & 30 & 200 & & 100 & 2000 & 300 & 6000 & 600 & 12000 & & 12000 & & 2000 \\
\hline Clortetraciclina & 100 & 30 & 200 & 400 & 100 & 2000 & 300 & 6000 & 600 & 12000 & & 12000 & & 2000 \\
\hline \multicolumn{15}{|l|}{ Sulfonamidas } \\
\hline Residuo total de sulfonamida & 100 & & & & 100 & & 100 & & 100 & & 100 & & & \\
\hline Sulfabromometazina (ganado) & & 10 & & & & 100 & & 100 & & 100 & & 100 & & \\
\hline Sulfacloropiridazina (pollos) & & & & & & 0 & & 0 & & 0 & & 0 & & \\
\hline Sulfacloropiridazina (terneros, cerdos) & & & & & & 100 & & 100 & & 100 & & 100 & & \\
\hline Sulfadimetoxina & & 10 & & & & 100 & & 100 & & 100 & & 100 & & 100 \\
\hline Sulfaetoxipiridazina (ganado) & & 0 & & & & 100 & & 100 & & 100 & & 100 & & \\
\hline Sulfaetoxipiridazina (cerdo) & & & & & & 0 & & 0 & & 0 & & 0 & & \\
\hline Sulfamerazina (trucha) & & & & & & & & & & & & & & 0 \\
\hline Sulfametazina & & & & & & 100 & & 100 & & 100 & & 100 & & \\
\hline Sulfanitran (pollos) & & & & & & 0 & & 0 & & 0 & & 0 & & \\
\hline Sulfaquinoxalina & & & & & & 100 & & 100 & & 100 & & 100 & & \\
\hline Sulfatiazol (cerdo) & & & & & & 100 & & 100 & & 100 & & 100 & & \\
\hline \multicolumn{15}{|l|}{ Quinolonas } \\
\hline Danofloxacina (ganado) & NP & & & & 200 & & 400 & & 400 & & 100 & & & \\
\hline Danofloxacina (pollos) & & & NP & & 200 & & 400 & & 400 & & 100 & & & \\
\hline Decoquinato (ganado) & & & & & 500 & & 500 & & 500 & & 500 & & & \\
\hline Difloxacina (pollos, pavos) & & & & & 300 & & 1900 & & 600 & & 400 & & & \\
\hline Enrofloxacina (pollos, pavos) & & & & & 30 & 300 & 30 & & 30 & & & & & \\
\hline Enrofloxacina (ganado) & & & & & 30 & & 30 & 100 & 30 & & & & & \\
\hline Enrofloxacina (cerdo) & & & & & 30 & & 30 & & 30 & & & & & \\
\hline Marbofloxacina (ganado) & & & & & 150 & & 150 & & 150 & & 50 & & & \\
\hline Marbofloxacina (cerdo) & & & & & 150 & & 150 & & 150 & & 50 & & & \\
\hline Sarafloxacina (pollos, pavos) & & & & & & NR & 100 & NR & & NR & 10 & NR & & \\
\hline Sarafloxacina (salmon) & & & & & & & & & & & & & 30 & \\
\hline Cloranfenicol (MRPL) & 0.3 & & 0.3 & & & & & & & & & & & \\
\hline
\end{tabular}

Los escasos controles en este tema dejan de manifiesto y abierta la posibilidad, de que el uso de sustancias permitidas se encuentren fuera de los límites mínimos recomendados por el Codex alimentarius (Márquez 2008, Lozano \& Arias 2008).

Problemas en el Medio Ambiente: Algunos de los antibióticos administrados como promotores del crecimiento se absorben poco en el tracto gastrointestinal de los animales, eliminándose a través de las heces a elevadas concentraciones. Otros antibióticos, por el contrario, se absorben a nivel intestinal, los cuales pueden ser eliminados por la orina dispersándose estas sustancias en el medio ambiente.
Cada vez aparecen más estudios que describen la detección de residuos de antibióticos en agua (Ferrer \& Thurman 2012) y sedimentos y estudian los efectos negativos que pueden ejercer a mediano y a largo plazo en los organismos y microorganismos que habitan en los ecosistemas. En algunos sedimentos cercanos a explotaciones ganaderas se ha detectado un aumento de cepas bacterianas resistentes a algunos antibióticos. Aun, se siguen efectuando estudios para obtener más información acerca de su persistencia en el medio ambiente, empleándose para tal fin la técnica de Cromatografía Líquida- Espectrometría de Masas Tandem (LC-MS/MS; Petrovic et al. 2005, Sarmah et al. 2006, Gratacós 2007). 
El uso de antibióticos como promotores del crecimiento animal: Los antibióticos son sustancias naturales o sintéticas con actividad farmacológica que se administran a los animales sanos a través de los piensos para acelerar la ganancia de peso y mejorar los índices de transformación de los alimentos; aunque afectan la microbiota normal. Actualmente se admite el uso de la monensina, salinomicina, flavofosfolipol y avilamicina. Como informan Cancho et al. (2000) y Gimeno (2001) los promotores de crecimiento pueden ser de tres tipos:

1. Antibióticos y quimioterapéuticos de actuación sobre la microflora bacteriana del tubo digestivo, en concentraciones entre 30 y $100 \mathrm{mg} / \mathrm{L}$, administrados sistemáticamente durante largos periodos.

2. Sustancias ionóforas que actúan sobre el rumen.

3. Anabolizantes, generalmente sustancias de tipo hormonal, los cuales actúan como promotores de crecimiento mediante una acción sobre el metabolismo.

En la práctica agrícola moderna, los medicamentos veterinarios se están utilizando a gran escala y administrados como aditivos para piensos o el agua de bebida con el fin de inhibir el brote de enfermedades. Además, las drogas veterinarias se dan en los casos de enfermedad, para la deshidratación o para prevenir las pérdidas durante el transporte. La promoción de agentes del crecimiento (por ejemplo, hormonas y ciertos medicamentos veterinarios, principalmente antibióticos) se aplican para estimular el crecimiento de los animales (Fajardo et al. 2011). Por esta situación, la Unión Europea desde el 1 de enero de 2006 ha establecido por Reglamento 1831/2003 una moratoria para el uso de coccidiostáticos e histomonostáticos. Algunos antibióticos usados como promotores de crecimiento, tales como la avoparcina, la espiramicina, la bacitracina, la tilosina y la virginamicina, por ser todas sospechosas de contribuir a la aparición de nuevas cepas bacterianas resistentes a los antibióticos (Stolker et al. 2007, Bogialli \& Di Corcia 2009); Por tal motivo, el Codex alimentarius, la Comunidad Europea (CE) y los gobiernos de Japón, Estados Unidos, entre otros, establecen límites máximos residuales (LMRs) para regular cada sustancia no autorizada en un alimento en particular (Le Bizec et al. 2009). Así mismo el Codex lo hace para asegurar la inocuidad para el consumo humano. Debido a estos efectos, se han propuesto varias alternativas a los antibióticos utilizados como promotores de crecimiento. Estas alternativas consisten en utilizar sustancias de origen natural que presenten un efecto antibacteriano directo o indirecto como algunas enzimas, ácidos orgánicos, prebióticos, oligosacáridos, aceites, extractos vegetales, vitaminas y micro-minerales.

Técnicas instrumentales utilizadas en la identificación y cuantificación de residuos de fármacos y antibióticos en alimentos de origen animal: Dada la necesidad de detectar y cuantificar los residuos de antibióticos en alimentos de origen animal, desde la segunda mitad del siglo veinte son múltiples los métodos analíticos desarrollados ó modificados de los ya existentes, siendo las técnicas cromatográficas las de más amplio alcance. (Figura 1).

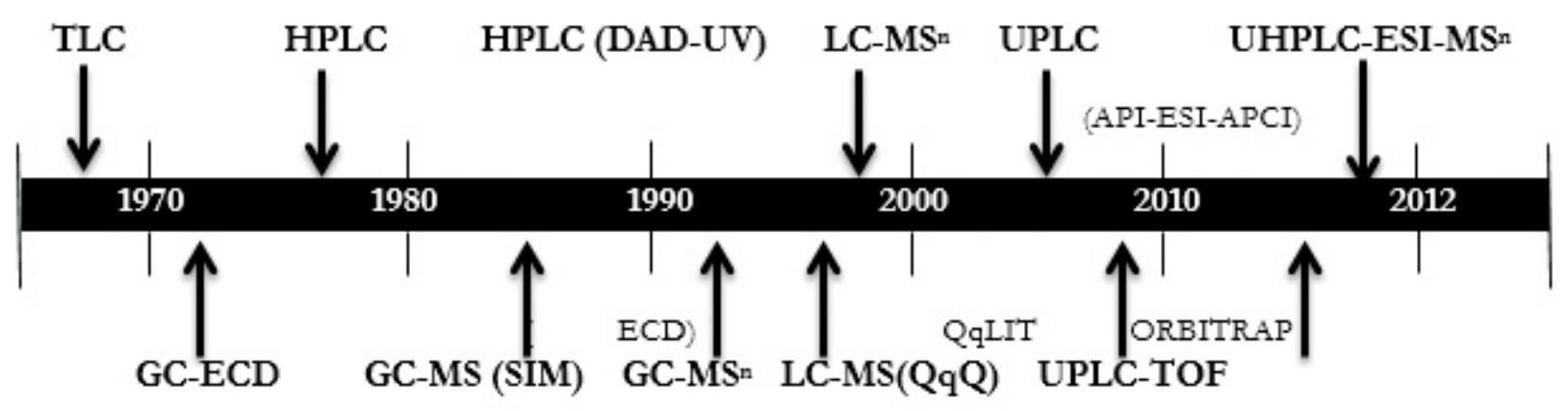

Fig. 1. Evolución de las técnicas analíticas empleadas. QqQ: triple cuadrupolo, QTI: cuadrupolo con trampa de iones, TOF: Tiempo de vuelo, QqTOF: cuadrupolo tiempo de vuelo, TLC: cromatografía en capa fina. 
Dentro de las técnicas existentes hoy en día se destacan el empleo de biosensores por inmunoabsorción ligado a enzimas (ELISA), el cual permite manejar gran número de muestras debido a su bajo costo y facilidad operativa, siendo un ensayo rápido para la evaluación cualitativa y presuntiva de los antibióticos en los alimentos de origen animal. Aunque su especificidad y sensibilidad depende del antibiótico a analizar, siempre se tendrá que utilizar métodos de confirmación los cuales permiten obtener información adicional para la cuantificación e identificación inequívoca del analito (Comisión Europea. Decisión de la Comisión 2002/657/CE) (Sawaya et al. 1998, Montoya 2002, Toldrá \& Reig 2006, Reig 2010, Gallego 2012).

Como técnicas de confirmación se utilizan, generalmente, cromatografía de gases (GC) y cromatografía líquida de alta resolución (HPLC). Cuando se emplea la cromatografía de gases acoplada a la espectrometría de masas (GC/MS), las sulfonamidas y tetraciclinas requieren una derivatización previa para aumentar su volatilidad y originar fragmentos de masa molecular adecuados para el análisis de trazas.

Sin embargo, los métodos cromatográficos no están exentos de inconvenientes. Por ello, es pertinente evaluar los factores que limitan sus costos de implementación (equipamiento, capacitación técnica, infraestructura de laboratorios, costo por análisis, tiempo entre la recolección y el resultado); destacando la dificultad de analizar grandes volúmenes de muestras en tiempos reducidos, indispensable para llevar a cabo programas de vigilancia y control efectivos, o el requerimiento de tratamientos de muestra laboriosos y equipos costosos, por lo que es necesario desarrollar nuevos métodos simples y rápidos (Gallego 2012).

La Cromatografía Líquida (LC): La cromatografía es el nombre que se le da a un grupo de técnicas utilizadas en la determinación de la identidad, cuantificación y separación de sustancias en una mezcla, las cuales se basan en el mismo principio: todos los sistemas de cromatografía abarcan una fase estacionaria y una fase móvil. La cromatografía Líquida comprende todas las técnicas cromatográficas que usan una fase móvil líquida, entre las cuales están la cromatografía de papel, la cromatografía en capa fina, la cromatografía en columna y la cromatografía líquida de alta eficiencia (HPLC).
HPLC: Es una técnica separativa y su poder para discriminar una sustancia de otra va a depender del detector. La elección del sistema de detección es muy importante para la selectividad y sensibilidad del analito a identificar; el detector de arreglo de diodos (DAD) o detector ultravioleta (UV) han sido utilizados para la detección de antibióticos en carne, riñón y leche, según Informe Técnico Organización Mundial de la Salud (OMS) del año 2000 (Poucke et al. 2003).

El empleo de LC con detector UV o DAD (Detector con Arreglo de Diodos), se ha empleado en la determinación de bacitracina de zinc (Capitán VL et al. 2001), y para el análisis de residuos de sulfonamidas presentes en distintas matrices de animales; este método se caracteriza por su mayor sencillez y rápidez (Di Corcia \& Nazzari 2002, Stolker \& Brinkman 2005, Gratacós 2007), mientras que GC-MS (Cromatografía de gases con detector de masas) es aplicada para efectos confirmativos. Sin embargo, es importante tener en cuenta que la robustez del procedimiento es un factor al momento de elegir el método analítico adecuado para fines reglamentarios. La HPLC, resulta la más indicada para el análisis de antibióticos en pescados, dado que se caracterizan por ser termolábiles y polares, (Sorensen et al. 1999, Yorke \& Froc 2000, Pena et al. 2003, JungBin et al. 2007). La cromatografía líquida de ultra-alta presión (UHPLC) acoplado con espectrometría de masas cuadrupolar y tiempo de vuelo (UHPLC-MSQTOF), se ha empleado para la detección de residuos de múltiples antibióticos (Bogialli \& Di Corcia 2009, Jin et al. 2010, O’Mahony et al. 2013) en diversas matrices biológicas como el riñón, músculo e hígado (Kaufmann et al. 2008, Gros et al. 2012).

Recientemente se desarrolló un método basado en la cromatografía líquida de interacción hidrofilica alta presión electrospray acoplado a Tándem (HILICUPLC-ESI-MS/MS; Chiaochan et al. 2010). Este permitió analizar 24 residuos de medicamentos en músculo de pollo, el cual se caracterizó por mostrar una mejoría en separación de los analitos en estudio, mejorando la forma de las señales y la sensibilidad para la detección de los mismos.

Cromatografía Líquida Espectrometría de Masas (LC-MS): Las agencias de salud pública en muchos países se basan en la detección por espectrometría de masas para la identificación inequívoca de 
los residuos de agentes antimicrobianos en los productos alimenticios de origen animal destinados al consumo humano. La introducción de esta técnica es relativamente de fácil acceso y robusta. $\mathrm{Al}$ respecto el sistema LC-MS ha dado un fuerte impulso al desarrollo de nuevos y mejores métodos para determinar y confirmar la presencia de residuos de medicamentos en matrices alimentarias.

Tres aspectos han incidido en el desarrollo de las interfaces de LC-MS:

1. La volatilización del efluente de la columna, la eliminación de los constituyentes de la fase móvil, la volatilización del analito y posterior ionización.

2. La ionización directa del efluente, como por ejemplo, la ionización por bombardeo del flujo del analito en la interface.

3. La volatilización del efluente de la columna a presión atmosférica o a una presión reducida, desolvatación de las gotas, seguida de la ionización química en fase gaseosa o iónica por ejemplo, evaporación, termospray, electronebulización (ESI) y la interface caliente del nebulizador APCI. En la práctica, la interface elegida impone limitaciones tanto para la metodología aplicable LC (velocidad del flujo y la composición del disolvente) y la técnica de ionización aplicable en la MS. (Niessen 1998).

En la práctica, la interface elegida determina las limitaciones tanto en la metodología cromatográfica a elegir (caudal y composición del disolvente), como también en la técnica de ionización para la espectrometría de masas (MS).

Entre los diferentes analizadores de masas habitualmente empleados para el análisis elegido, el sistema triple cuadrupolo (QqQ) es el más utilizado para la medición y cuantificación de los residuos de medicamentos veterinarios (Kellmann et al. 2009, Bogialli \& Di Corcia 2009). La trampa de iones convencional (IT) proporciona espectros de masas de óptima resolución que permiten realizar experimentos de caracterización estructural para confirmar la estructura molecular de los metabolitos. El cuadrupolo lineal IT (QqLIT) es un sistema funcional que combina QqQ y LIT-MS completamente en el mismo instrumento. Una tendencia reciente hacia la popularización de los analizadores de masas de alta resolución (HRMS) como el TOF (por sus siglas en inglés de Time Of Flight), está dada por la exactitud, la velocidad y la selectividad para generar el espectro de masas (Le Bizec et al. 2009, Bogialli \& Di Corcia 2009, Ferrer \& Thurman 2012, Farré \& Barceló 2012, Di Stefano et al. 2012).

\section{Cromatografía Líquida acoplado a espectrometría} de masas (LC-MS): Es una técnica robusta, sensible y selectiva, y se ha convertido en una técnica muy difundida para el análisis cuantitativo y cualitativo (Yoshida et al. 2009). También se emplea en la detección de residuos de medicamentos veterinarios en huevos, leche, pescados y carne (Aerts et al. 1995, Horie et al. 1998, Reig 2010). Dado que la técnica de GC-MS requiere de pretratamiento de la muestra y derivatización del analito, la LC-MS es una alternativa que requiere menos complejidad para la determinación de sulfonamidas; la mayoría de los métodos LC-MS publicados para el análisis de este tipo de fármacos se basan en la HPLC/APSI-MS y HPLC/ESI-MS (Combs et al. 1997, Kennedy et al. 1998, Niessen 1998, Tarbin et al. 1999, Fuh \& Chan 2001, Di Corcia \& Nazzari 2002, Gentili et al. 2004, MsGati \& Nindi 2004, Stolker \& Brinkman 2005, Gentili et al. 2005, Bogialli \& Di Corcia 2009). Algunos métodos se basan en la derivatizacion post columna (Gehring et al. 1997, Smallidge \& Albert 2000, Maudens et al. 2004) o precolumna (Takeda \& Akiyama 1991, Tsai \& Kondo 1995, Simeonidou et al. 1996) con fluosesencia (FLD).

Los primeros trabajos que utilizaron métodos LC-MS para analizar promotores de crecimiento emplearon fuentes de ionización por termopulverización (TSP). Posteriormente y siguiendo la evolución de las técnicas de ionización en espectrometría de masas acoplada a la cromatografía líquida, la TSP fue desplazada por las técnicas de ionización a presión atmosférica (API), que incluyen la electronebulización o electrospray (ESI) y la ionización química a presión atmosférica (APCI); sin embargo, ESI sigue siendo la fuente de iones más utilizada para el análisis de antibióticos en los alimentos, debido a la alta polaridad que presentan estas sustancias (Maurer et al. 2004, Puente 2004, Turnipseed et al. 2005, Reig \& Toldrá 2008, Bogialli \& Di Corcia 2009, Rodríguez et al. 2013). 
Acoplamiento TANDEM (MS $\left.{ }^{n}\right)$ : La espectrometría de masas, ya sea en modo simple MS o en tándem (MS/MS), es la técnica de detección más extendida (Dorge \& Bajic 1995, Volmer et al. 1997, Johnston et al. 2002, Hewitt et al. 2002, Thevis et al. 2003, Huetos 2004, Romero et al. 2007, Guy et al. 2007, Ramírez et al. 2007, Stolker et al. 2007, Ackermann et al. 2008, Le Bizec et al. 2009, Jin et al. 2010, Macarov et al. 2012). La espectrometría de masas, sin duda alguna, la técnica analítica instrumental más completa que existe actualmente. Entre las cualidades que justifican esta afirmación, podemos citar, su capacidad de identificación, análisis de muestras complejas, alta sensibilidad, caracterización estructural e isotópica de moléculas, por lo cual es considerada, universal, específica y relativamente rápida. El acoplamiento cromatografía líquida-espectrometría de masas (LCMS/MS) es especialmente adecuado para el análisis en química ambiental debido a su gran sensibilidad y selectividad; también se ha utilizado en el análisis de residuos de medicamentos veterinarios.

Además, se conoce que la sensibilidad y la especificidad son dos características importantes para el análisis de trazas y la detección de un analito. Al respecto, el acoplamiento MS/MS presenta grandes ventajas prácticas respecto a MS simple, debido a que mejora la calidad y la cantidad de la información en términos de selectividad y elucidación estructural. Este tipo de acoplamiento junto con cromatografía de gases o la cromatografía líquida, ofrece una poderosa combinación, siendo ampliamente considerada como la técnica más definitiva para aspectos de tipo normativo. Por ello, entre sus aplicaciones actuales más reconocidas se puede mencionar los ensayos de fármaco-cinético, detección de interferencia de fondo, separación de componentes de mezclas con diferentes pesos moleculares, la fragmentación controlada y reproducible, y el monitoreo de reacciones, entre otras.

Entre las aplicaciones más representativas podemos mencionar un estudio que permitió la determinación de bacitracina de zinc en matrices alimentarias (Hajee et al. 2001). De forma análoga se logró determinar la presencia de avoparcina, espiramicina, tilosina y virginamicina, prohibidos como promotores de crecimiento (Gimeno 2001), por cromatografía líquida en fase reversa-espectrometría de masas (LC-ESI-MS/ MS). La viginamicina también ha sido cuantificada por LC-MS (Poucke et al. 2003).
Contribución de la Cromatografía de gases, GC-MS y electroforesis capilar: Técnicas que acopladas identifican residuos compuestos polares y no volátiles (Balizs \& Hewitt 2003) y residuos de origen animal.

Cromatografía de gases y GC-MS: GC-MS es una técnica analítica separativa ampliamente utilizada para la separación de compuestos volátiles e isotopos atómicos, dependiendo de sus puntos de ebullición. Esta técnica ha sido la más empleada por exactitud, sensibilidad y reproducibilidad, dado que permite la separación e identificación de mezclas complejas. Luego de su separación las moléculas del analito son bombardeadas por electrones rompiendo los enlaces (en ocasiones no necesariamente), generando fragmentos moleculares cargados, los cuales son propios de la naturaleza de cada compuesto. Dado que este proceso requiere volatilizar el analito, la técnica GC-MS no es muy apropiada para analizar residuos de medicamentos, debido a que en su gran mayoría poseen altos pesos moleculares, pero si fueran sustancias volátiles GC-MS seria la técnica más adecuada. Otro factor que incide en la aplicación de este método es la inestabilidad térmica de los analitos y la falta de volatilidad de muchos antibióticos que hacen que la técnica GC-MS sea de difícil aplicación. Además, la cromatografía de gases (GC) es una técnica muy sensible y específica, pero la aplicación rutinaria de este método no es fácil para un gran número de muestras, debido a la purificación y múltiples pasos requeridos para la derivatización (Kowalski et al. 2003, Yoshida et al. 2009). Por esta razón (LC-MS/MS) es la técnica complementaria de GC-MS más adecuada debido a su amplia aplicabilidad para la determinación de compuestos polares y no volátiles (Balizs \& Hewitt 2003).

Electroforesis Capilar (CE): La electroforesis capilar (CE) permite la extracción selectiva y la concentración de los residuos veterinarios en materiales de relativa complejidad, siendo a menudo una operación de un solo paso, con un rendimiento comparativamente alto. CE se ha convertido en una herramienta muy útil para el análisis farmacéutico debido a su alta velocidad de resolución, y al reducido volumen de muestra que es requerido. Sin embargo, el uso de CE en bioanálisis de medicamentos está restringido debido a la baja sensibilidad de la técnica (Huertas 2008). Una forma de mitigar el problema de determinar analitos que 
estén a muy bajas concentraciones, es la aplicación procedimientos de preconcentración, los cuales han demostrado ser útiles posibilitando determinar concentraciones inferiores al LMR admisible en los productos animales. Los electroforegramas muestran una buena resolución y no hay interferencia con otras señales, lo que indica una adecuada especificidad y sensibilidad de este método para muestras de músculo, hígado, riñón y piel con grasa (Kowalski et al. 2003).

$\mathrm{Al}$ respecto, estudios han demostrado la presencia de residuos de quinolonas y otros tipos de antibióticos en alimentos de origen animal, mediante electroforesis capilar acoplada a espectrometría de masas cuadrupolar con ionización por electrospray (ESI; García et al. 2005; García et al. 2007). Recientemente se ha utilizado la electroforesis capilar (CE) con detector UV para la determinación de residuos de tetraciclina (Kowalski 2008).

Las técnicas de interface más empleadas (Tabla 2) para la determinación de residuos de medicamentos en diferentes matrices alimentarias; se resumen a continuación.

Tabla 2. Opiniones publicadas recientemente. TLC: Cromatografía en capa fina, FLD: Detector de fluorescencia, ITD: detector de trampa de iones, ESI: Ionización por electro-spray, CE: Electroforesis capilar, ECD: Detector de captura de electrones, QqQ: triple cuadrupolo, Q-TOF: cuadrupolo tiempo de vuelo, HILIC: Cromatografía líquida-interacción hidrofilica, DAD: Detector de diodos, $\mathbf{M S}^{\mathrm{n}}$ : Tándem.

Tabla 2. Opiniones publicadas recientemente

\begin{tabular}{|c|c|c|c|}
\hline Muestra & $\begin{array}{l}\text { Clase de } \\
\text { medicamento veterinario }\end{array}$ & $\begin{array}{l}\text { Técnica } \\
\text { analítica especifica }\end{array}$ & Referencias \\
\hline $\begin{array}{l}\text { Tejidos animales, leche, miel, } \\
\text { hígado y productos pesqueros }\end{array}$ & $\begin{array}{l}\text { Agentes promotores } \\
\text { de crecimiento, antibióticos }\end{array}$ & $\begin{array}{l}\text { HPLC-DAD o UV; } \\
\text { LC-MS, LC-ESI-MS }\end{array}$ & $\begin{array}{l}\text { Ackermann et al. 2008, Montoya 2002, García et al. 2007, } \\
\text { Guy et al. 2007, Niessen } 2003 .\end{array}$ \\
\hline Piensos para animal & Bacitracina de Zinc & LC-UV o FLD; LC-ESI-MS/MS & Gimeno 2001, Capitán 2001. \\
\hline Agua & Productos farmacéuticos & LC-Q-TOF/MS, LC-MS & $\begin{array}{l}\text { Gentili et al. 2004, Fajardo et al. 2011, } \\
\text { Montalvo et al. 2004, Petrovic et al. } 2005 .\end{array}$ \\
\hline $\begin{array}{l}\text { Huevos, leche, pescado, músculo de } \\
\text { ovino, músculo de pollo, riñón de } \\
\text { porcino, pescado, hígado }\end{array}$ & Quinolonas; & LC/FLD; LC-MS/MS & $\begin{array}{l}\text { P.T.I.N.S. 1990, Consentino 2009, Aerts et al. 1995, } \\
\text { Romero et al. 2007, Gratacós 2007, Lozano \& Arias 2008, } \\
\text { Bogialli \& Di Corcia 2009, Reig } 2010 .\end{array}$ \\
\hline Tejidos animales, miel, leche, huevos & Sulfonamidas & $\begin{array}{l}\text { LC-UV/FLD/MS; } \\
\text { LC-ESI-MS/MS; TLC; CE }\end{array}$ & $\begin{array}{l}\text { P.T.I.N.S. 1990, Gentili et al. 2004, Consentino 2009, } \\
\text { Bogialli \& Di Corcia 2009, Romero et al. } 2007 .\end{array}$ \\
\hline Leche & Quinolonas, sulfonamidas & $\begin{array}{l}\text { Separación: HPLC (C18); } \\
\text { Técnica MS/MS }\end{array}$ & Bohm DA et al. 2009. \\
\hline $\begin{array}{l}\text { Pescado incluyendo el músculo, } \\
\text { la cabeza, branquias, intestino } \\
\text { y tejidos en agua }\end{array}$ & Cloranfenicol & LC-ESI-MS/MS & Kennedy et al. 1998. \\
\hline $\begin{array}{l}\text { Bovinos, porcinos, músculo de aves } \\
\text { de corral, pescado, leche y } \\
\text { tejidos de camarón }\end{array}$ & Cloranfenicol & $\begin{array}{l}\text { LC-UV, ITD; así como } \\
\text { GC-ECD, LC-MS/MS(QqQ) }\end{array}$ & $\begin{array}{l}\text { P.T.I.N.S. 1990, García et al. 2005, } \\
\text { Jung et al. 2007, Aerts et al. 1995, } \\
\text { Bogialli \& Di Corcia 2009, Kennedy et al. } 1998 .\end{array}$ \\
\hline Riñón, músculo, hígado & Diferentes antibióticos & UPLC-MS-QTOF & $\begin{array}{l}\text { Huetos 2004, Hewitt et al. 2002, } \\
\text { Bogialli \& Di Corcia } 2009 .\end{array}$ \\
\hline Músculo de pollo & 24 diferentes residuos & HILIC-UPLC-ESI-MS/MS & Chiaochan et al. 2010. \\
\hline \multicolumn{2}{|c|}{ TLC, Cromatografía en capa fina } & \multicolumn{2}{|c|}{ FLD, Detector de fluorescencia } \\
\hline \multicolumn{2}{|c|}{ ITD, detector de trampa de iones } & \multicolumn{2}{|c|}{ ESI, Ionización por electro-spray } \\
\hline \multicolumn{2}{|c|}{ CE, Electroforesis capilar } & \multicolumn{2}{|c|}{ ECD, Detector de captura de electrones } \\
\hline \multicolumn{2}{|c|}{ QqQ, triple cuadrupolo } & \multicolumn{2}{|c|}{ Q-TOF, cuadrupolo tiempo de vuelo } \\
\hline \multicolumn{4}{|c|}{ HILIC, Cromatografía líquida-interacción hidrofilica } \\
\hline \multicolumn{2}{|c|}{ DAD, Detector de diodos } & \multicolumn{2}{|c|}{ MS , Tándem } \\
\hline
\end{tabular}


En términos generales, la evolución que han tenido estas técnicas analíticas a lo largo de los años, ha sido el resultado del desarrollo de múltiples áreas de investigación como el análisis medioambiental (Ferrer \& Thurman 2012), el desarrollo de nuevos fármacos, el análisis de residuos de medicamentos veterinarios, la caracterización de productos naturales y de bio-moléculas tales como los péptidos, proteínas, oligosacáridos, lípidos y oligonucleótidos (Niessen 1999, Niessen, 2003, Toldrá \& Reig 2006, Romero et al. 2007, Reig 2010).

Antibióticos comúnmente detectados en alimentos de origen animal: Se presenta una visión general de algunos de los antibióticos más empleados en la práctica veterinaria y que se han detectado en alimentos; como es el caso del cloranfenicol, un antibiótico de amplio espectro que solo debe ser considerado como un medicamento de reserva, cuando no existan otras alternativas terapéuticas; debido a los efectos de resistencia microbiana en la actualidad, junto con la indudable toxicidad que presentan, además, de sus efectos secundarios como fetotoxicidad, anemia aplástica, la supresión de la medula ósea, un mayor riesgo de leucemia infantil y el síndrome del bebé gris. En efecto, este antibiótico, que durante mucho tiempo se ha presentado por ser de fácil acceso y económico, sigue siendo ampliamente utilizado pero ha quedado limitado para su uso. Así mismo, en este apartado también se hablará de un grupo de medicamentos veterinarios con efecto anabólico, y que están dentro de las sustancias pertenecientes al grupo B según la directiva 96/23/EC, en donde se encuentran las sustancias antibacterianas: Sulfonamidas (sulfadiazina, sulfatiazola, sulfapiridina, sulfamerazina, sulfametazina, sulfamonometoxina, sulfaclorpiridazina, sulfaquinoxalina, sulfadimetoxina, entre otras); Por ejemplo, los residuos de las sulfonamidas (sulfadimetoxina, sulfametazina, sulfametoxazol) pueden causar rash cutáneo, así como afecciones endocrinas, particularmente en tiroides y pituitaria (Gallego 2012). Luego se encuentran las quinolonas (ácido oxolínico, cinoxacina), fluoroquinolonas (enrofloxacina, sarafloxacina, ciprofloxacina, danofloxacina; Stolker et al. 2007, Reig 2010), donde según la resolución ICA N 1966 de 1984 se reglamenta el uso de productos o sustancias antimicrobianas como promotores de crecimiento o mejorados de la eficiencia alimenticia. No obstante, se siguen hallando residuos en diferentes matrices alimentarias, siendo un asunto que afecta la salud pública y considerando necesario su estudio. Además, se describen las técnicas analíticas más empleadas para su identificación y cuantificación, las cuales se presenta a continuación:

Sulfonamidas: Son N-derivados de la 4-aminobencenosulfonamidas (sulfanilamida), comprenden un gran grupo de compuestos antibacterianos sintéticos, en el cual el átomo de nitrógeno amídico está parcialmente sustituido por un fragmento heteroarilo (heterociclo, sulfadiazina) responsable de las propiedades farmacocinéticas que presentan (Figura 2).

Algunos estudios indicaron que presentan propiedades carcinogénicas después de observar el desarrollo de adenomas en la glándula tiroides en animales de experimentación (Littlefield et al. 1989). Revalidando este hecho, algunos residuos de sulfonamidas en los alimentos son de interés debido

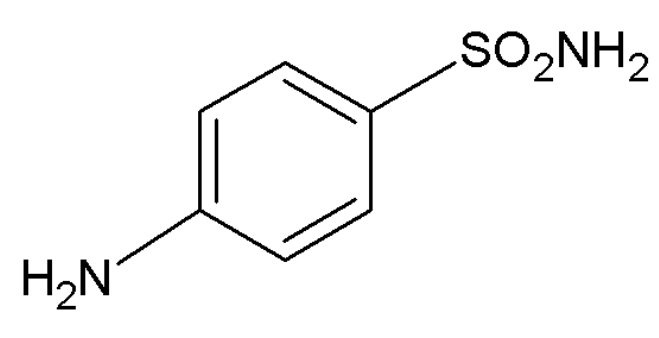

Sulfanilamida

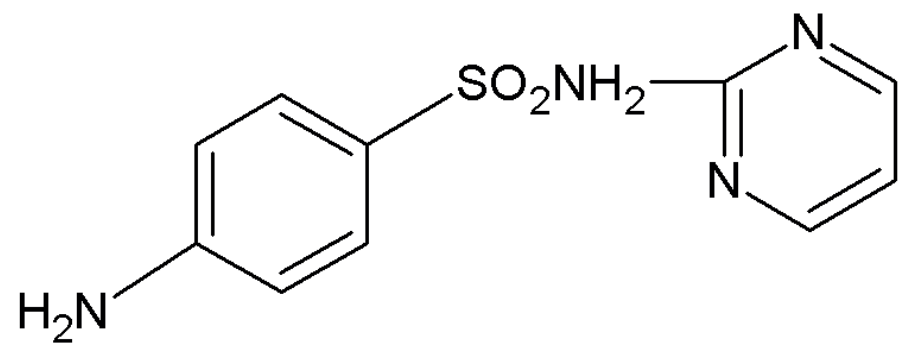

Sulfadiazina

Fig. 2. Estructura Química de las sulfonamidas. 
a su carácter cancerígeno potencial y la posibilidad de desarrollo de resistencia a los antibióticos en los microorganismos (Di Corcia \& Nazzari 2002, Stolker \& Brinkman 2005, Gratacós 2007, Bogialli \& Di Corcia 2009). Aunque las sulfonamidas se han utilizado en medicina humana contra una amplia variedad de microbios, el uso actual es principalmente en el tratamiento de infecciones del tracto urinario.

También se conoce, que este tipo de fármacos son ampliamente utilizados en piensos de animales de granja y en cultivos de peces como medicamentos para fines profilácticos y terapéuticos. Además, se sabe que el grupo de las sulfonamidas actúa como sustancias promotoras del crecimiento. La Unión Europea (UE) así como los organismos reguladores de Estados Unidos han establecido un límite máximo de residual de sulfonamidas en $100 \mathrm{mg} / \mathrm{kg}$; el nivel de regulación en la leche es de $10 \mathrm{mg} / \mathrm{kg}$ (Tabla 1).

Las sulfonamidas son antimicrobianos de amplio espectro, sus propiedades antibacterianas se deben a que son capaces de inhibir la producción del ácido fólico, necesario para la síntesis de ADN, impidiendo la reproducción de las células bacterianas. La analogía entre la estructura de las sulfonamidas y del ácido para-aminobenzoico (PABA), necesario para la síntesis del ácido fólico bacteriano, hace que actúen como antagonistas competitivos, debido a que se unen a la enzima tetrahidropteroicosintetasa necesaria para la condensación del ácido fólico. Este ácido es convertido en tetrahidrofolato, que actúa como coenzima en la transferencia de grupos metilo a las bases púricas y pirimidínicas para la síntesis del ADN y ARN (Pumarola et al. 1999).

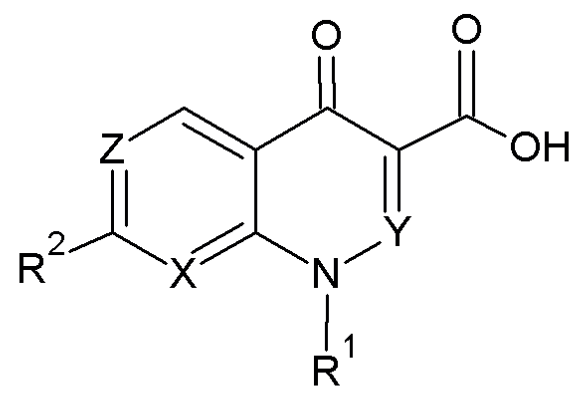

Estructura base de las quinolonas
De este modo, las sulfonamidas impiden la incorporación de PABA a la molécula de ácido fólico, dificultando su biosíntesis, etapa esencial para el crecimiento y la multiplicación bacteriana. Así pues, los microorganismos sensibles a las sulfonamidas son aquellos que deben sintetizar su propio ácido fólico, o bien son impermeables al ácido fólico de los líquidos circundantes (Gallego 2012).

La TLC (Cromatografía en capa fina) se ha utilizado como método de barrido derivatizando las sulfonamidas con fluorescamina para su detección. En el transcurso de los años, la TLC ha sido mejorada, pero sigue siendo una técnica poco precisa y de difícil cuantificación, por lo que se reserva como método de barrido. Además, esta metodología requiere laboriosas etapas de tratamiento de muestra y purificación con el fin de evitar interferencias, incrementando el tiempo de análisis y su costo.

Sin duda alguna, la técnica más utilizada como método de cuantificación y confirmación para el análisis de residuos de sulfonamidas y tetraciclinas, es la cromatografía líquida de alta resolución (HPLC) con distintos tipos de detección como UV y espectrometría de masas (Lindsey et al. 2001, Peng et al. 2008, Gallego 2012).

Quinolonas: Las quinolonas son compuestos heterocíclicos aromáticos que se caracterizan por que en su estructura química está presente el anillo de la piridona, con un grupo carboxilo libre o protegido en la posición 3. El nitrógeno generalmente tiene unido a un radical que puede ser una cadena lineal o un carbociclo (R1), siendo este último sustituyente responsable en gran medida de la actividad biológica (Figura 3).

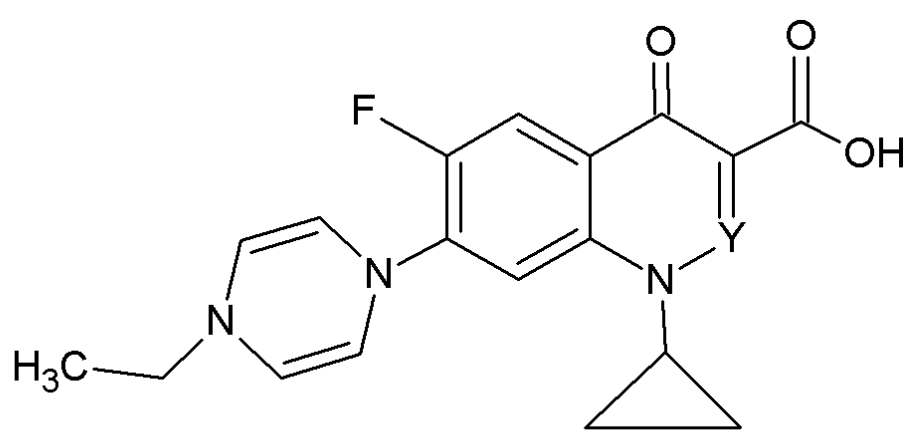

Estructura de la enrofloxacina

Fig. 3. Estructura Quimica de las quinolonas. 
Las quinolonas muestran una excelente actividad contra bacterias Gram-positivas y Gram-negativas. Estos compuestos actúan sobre los microorganismos sensibles inhibiendo la replicación del ácido desoxirribonucleico (ADN) bacteriano, careciendo de efecto sobre la síntesis nuclear de las células eucariotas (Hassouan 2006).

Las quinolonas son a menudo usadas en la industria ganadera y en los criaderos de peces, cuando se presentan cuadros infecciosos de tipo pulmonar, urinario y digestivo, dado que actúan como inhibidores bacterianos. Actualmente es una sustancia controlada, con el objetivo de minimizar el riesgo para la salud humana asociados con el consumo de sus residuos.

Uno de los métodos más utilizados para cuantificar quinolonas residuales es la Cromatografía Líquida de Alta Eficiencia (HPLC) con detector de fluorescencia (Nadezhda et al. 2012). Algunos estudios han mostrado que los mejores resultados de extracción del analito se obtuvieron con acetonitrilo y a diferentes $\mathrm{pH}$. $\mathrm{Al}$ respecto, se sabe que, por ejemplo, la enrofloxacina (Figura 3), una quinolona de uso veterinario, se encontró presente en muestras de pescado, músculo de pollo, músculo de ganado porcino, bovino y ovino (Yorke \& Froc 2000, Verdon et al. 2005).

También en años recientes se ha empleado un sistema analítico instrumental más moderno como la LC-MS/ MS (Cromatografía Líquida- Espectrometría de Masas Tandem) para identificar y cuantificar quinolonas en pollo e hígado de bovino, en músculo de bagre y cerdo, en leche y tejidos de salmón (Di Corcia \& Nazzari 2002, Balizs \& Hewitt 2003, Stolker \& Brinkman 2005, Hermo et al. 2006, Bogialli \& Di Corcia 2009).
Cloranfenicol (CAP): El cloranfenicol es una molécula orgánica, cuya estructura corresponde a un derivado del nitrobenceno, sustituido en la posición 4. En esta ramificación se encuentra presente un enlace tipo amida, como también la presencia de dos grupos hidroxilo y dos átomos de cloro. La presencia del anillo del nitrobenceno es relevante debido a que este se transforma en aminas aromáticas, las cuales pueden ser carcinogénicas (Balizs \& Hewitt 2003); la existencia del grupo hidroxilo facilita la formación de esteres que mejoran la hidrosolubilidad del antibiótico (Figura 4).

Es un antibiótico de amplio espectro frecuentemente utilizado en la producción de animales por sus excelentes propiedades antibacterianas y farmacocinéticas. Este antibiótico es muy efectivo pero puede inducir anemia aplástica y producir otros desórdenes sanguíneos a niveles muy reducidos (trazas). Estos efectos adversos han determinado la prohibición del cloranfenicol para el tratamiento de animales usados en la producción de alimentos (Balizs \& Hewitt 2003, Bogialli \& Di Corcia 2009). El cloranfenicol se fija a la subunidad $50 \mathrm{~S}$ del ribosoma tras penetrar por difusión facilitada en el citoplasma de la bacteria, al ser una molécula pequeña y no polar. La unión al ribosoma se realiza de tal forma que impide la fijación del aminoacil ARNt, al inhibir de forma reversible la peptidil transferasa, por lo que se detiene la síntesis proteica. El cloranfenicol podría inhibir también la síntesis proteica en células eucariotas, lo que justificaría en gran medida algunos aspectos de su toxicidad. La consecuencia para la bacteria sensible es la inhibición de su multiplicación, por lo que el efecto es bacteriostático en bacterias susceptibles (Uberos 2005).

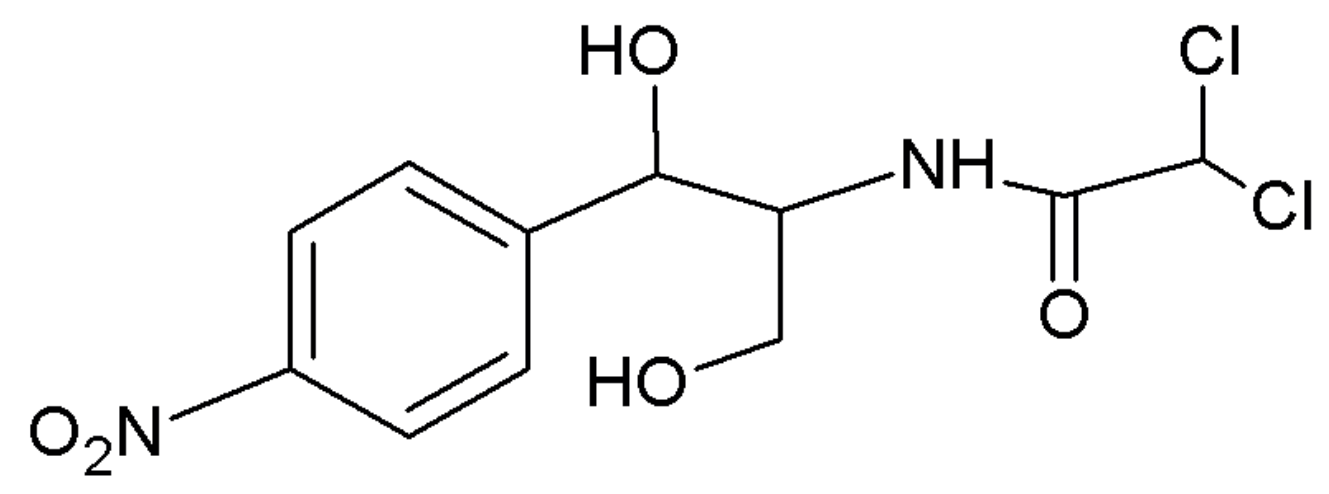

Fig. 4. Estructura Química del cloranfenicol. 
El cloranfenicol, en estado libre tiene muy baja solubilidad en agua, pero es altamente soluble en lípidos. Las sales de palmitato presentan características similares de solubilidad a diferencia de las de succinato que son altamente solubles en agua. Al tratarse de una sustancia prohibida, la UE ha establecido un MRPL para el cloranfenicol.

Respecto a los métodos analíticos de cuantificación, la cromatografía de gases y la líquida de alta eficiencia (HPLC), iniciaron su desarrollo y aplicación en la década de los 70s. Los procedimientos de preparación de la muestra en estos métodos involucran extracción con solventes y procesos de partición con mezcla de solventes. En años más recientes, la técnica más empleada para cuantificar cloranfenicol es HPLC acoplada a espectrometría de masas (Montoya 2002, Stolker \& Brinkman 2005).

La diferenciación y aplicación de los métodos descritos para identificar y cuantificar la presencia de residuos de antibióticos en alimentos, está basada en la capacidad de detección y practicidad del método para medir niveles trazas en el tejido objetivo. Para propósitos de selección, la electroforesis capilar, cromatografía electrocinética micelar y ensayos de resonancia de plasmones superficiales se han utilizado para el análisis de residuos de múltiples fenicoles (cloranfenicol es un tipo de fenicol) en diferentes matrices. Cromatografía líquida acoplada a detector UV así como GC-ECD (cromatografía de gases con detector de captura de electrones) también se han utilizado para la determinación de la CAP en los bovinos, porcinos, músculo de aves de corral, pescado, leche y tejidos de camarón (Le Bizec et al. 2009). Sin embargo, los métodos que utilizan cromatografía acoplada a espectrometría de masas (LC-MS/MS), sigue siendo el método recomendado para confirmar inequívocamente la presencia de cloranfenicol en diferentes matrices alimentarias (Balizs \& Hewitt 2003, Stolker \& Brinkman 2005, Gentili et al. 2005, Le Bizec et al. 2009, Bogialli \& Di Corcia 2009, Lu et al. 2009).

\section{Conclusión}

Eluso indiscriminado de fármacos como el cloranfenicol, las sulfonamidas y las quinolonas en la industria veterinaria como suplemento alimenticio, para tratar enfermedades en animales y favorecer el crecimiento, ha ocasionado la aparición de gérmenes antibióticoresistentes, provocando múltiples alteraciones patológicas, toxicidades crónicas o subcrónicas según los casos. El impacto que ha tenido este tipo de prácticas en aspectos médicos, veterinarios, económicos y en la de muchos países, no tiene paralelo en la historia de la terapéutica medica. Esta problemática de salud pública internacional ha permitido el desarrollo y validación de métodos analíticos para la determinación y cuantificación de residuos de cloranfenicol, sulfonamidas y quinolonas.

Al respecto la cromatografía de gases y cromatografía líquida en combinación con los diversos analizadores de masas, son las técnicas instrumentales más empleadas actualmente para la determinación y cuantificación de cloranfenicol, las sulfonamidas y las quinolonas. Las tecnologías más recientes son las de trampa de iones lineal (LIt), trampa orbital (Orbitrap) y la nueva generación de instrumentos híbridos, tales como, el cuadrupolo de tiempo de vuelo (QqTOF), trampa de cuadripolo lineal (Qq-Lits) o trampas lineal de orbitales (LTQ-Orbitrap), que están ganando una amplia aceptación en varias áreas de aplicación. Todos estos instrumentos ofrecen ventajas como análisis rápidos, mediciones exactas de masa (QqTOF, LTQ-Orbitrap) y altas sensibilidades (LIt y la nueva generación de QqQ). El rango de aplicación de la espectrometría de masas multidimensional es hoy en día extremadamente amplio, en términos de los compuestos de interés.

Con el desarrollo de nuevas técnicas e interfaces que involucran sistemas de ionización a presión atmosférica, ionización por electrospray y de ionización química a presión atmosférica, la introducción de las tecnologías cuadrupolares y sistemas tándem, han permitido la determinación de compuestos con masa molecular elevada y sustancias no volátiles, sin recurrir a la derivatización, entre los que se encuentran los fármacos de uso veterinario y agentes que promueven el crecimiento, los cuales han sido posible detectar, identificar y cuantificar satisfactoriamente.

Es necesario que las entidades responsables de vigilar la salud pública en el país determinen frecuentemente los niveles de sustancias permitidas como promotores de crecimiento y ajusten las recomendaciones y los niveles máximos. 


\section{Agradecimientos}

Los autores agradecen a la Dirección de Investigaciones de la Universidad Pedagógica y Tecnológica de Colombia por la financiación otorgada para realizar ésta investigación y su colaboración.

\section{Conflicto de intereses}

Los autores expresan que no existe conflicto de intereses.

\section{Referencias}

Ackermann BL, Berna MJ, Eckstein JA, Ott LW, and Chaudhary AK (2008) Current Applications of Liquid chromatography/Mass Spectrometry in Pharmaceutical Discovery After a Decade of Innovation. Annual Reviews 1:357-396

Aerts MM, Hogenboom AC, Brinkman UA (1995) Analytical strategies for the screening of veterinary drugs and their residues in edible products. Journal of Chromatography $B$ : Biomedical Applications 667:1-40

Balizs G, Hewitt A (2003) Determination of veterinary drug residues by liquid chromatography and tandem mass spectrometry. Analytica Cbimica Acta 492:105-131

Bohm DA, Stachel CS, Gowik P (2009) Multi-method for the determination of antibiotics of different substance groups in milk and validation in accordance with Commission Decision 2002/657/EC. Journal Chromatography A 1216:8217-8223 doi: 10.1016/j.chroma.2009.06.058

Bogialli S, Di Corcia A (2009) Recent applications of liquid chromatography-mass spectrometry to residue analysis of antimicrobials in food of animal origin. Analytical and Bioanalytical Chemistry 395:947-966 doi: 10.1007/s00216009-2930-6

Cancho GB, García FM, Simal GJ (2000) El uso de los antibióticos en la alimentación animal: perspectiva actual. Ciencia y Tecnología Alimentaría 3:39-47

Capitán VL, Navas N, Titos A, Checa R (2001) Determination of the antibiotic zinc bacitracin in animal food by highperformance liquid chromatography with ultraviolet detection. Chromatographia 54:15-20

Chiaochan Ch, Koesukwiwat U, Yudthavorasit S, Leepipatpiboon N (2010) Efficient hydrophilicinteraction liquid chromatography-tandem mass spectrometry for the multiclass analysis of veterinary drugs in chicken muscle. Analytica Chimica Acta 682:117-129

Combs MT, Boyd S, Khorassani AM, Taylor LT (1997) Quantitative Recovery of Sulfonamides from Chicken Liver, Beef Liver, and Egg Yolk via Modified Supercritical Carbon Dioxide. Journal of Agricultural and Food Chemistry 45:1779-1783 doi: 10.1021/jf960814s
Comisión Europea. Decisión de la comisión del 12 de agosto de 2002 por la que se aplica la Directiva 96/23/CE del Consejo en cuanto al funcionamiento de los métodos analíticos y la interpretación de los resultados notificada con el número C(2002) 3044 (2002/657/CE), Diario oficial de las comunidades Europeas, L221:8

Consentino M (2009) Desarrollo, Optimización y Validación de métodos analíticos para la determinación de antibióticos en productos pesqueros de interés comercial. Tesis de doctorado. Departamento de química analítica, Universidad de Sevilla, España.

CVMP (2001) Note for guidance on the risk analysis approach for residues of veterinary medicinal products in food of animal origin. EMEA/CVMP/187/00-FINAL

Di Corcia A, Nazzari M (2002) Liquid chromatographicmass spectrometric methods for analyzing antibiotic and antibacterial agents in animal food products. Journal of Chromatography A 974:53-89

DiStefano V,Avellone G, David B, Cunsolo V, Muccilli V,Sforza S, Dossena A, Drahos L, Vékey K. (2012) Applications of liquid chromatography-mass spectrometry for food analysis. Journal of Chromatograpby A 1259:74-85

Dorge D, Bajic S (1995) Multiresidue determination of quinolone antibiotics using liquid chromatography coupled to atmospheric-pressure chemical ionization mass spectrometry and tandem mass spectrometry. Rapid Comunications on Mass Spectrometry 9:1012-1016

Doyle ME (2006) Veterinary Drug Residues in Processed Meats Potential Health Risk; A Review of the Scientific Literature. Food Research Institute

Fajardo AL, Méndez FJ, Molina LH (2011) Residuos de fármacos anabolizantes en carnes destinadas al consumo humano. Universitas Scientiarum 16:77-91

Farré M, Barceló D (2012) Analysis of emerging contaminants in food. Trends in Analytical Chemistry 43:240-253 doi: 10.1016/j.trac.2012.12.003

Ferrer I, Thurman EM (2012) Analysis of 100 pharmaceuticals and their degradates in water samples by liquid chromatography/quadrupole time-of-flight mass spectrometry. Journal of Chromatography A 1259:148-157

Fuh MR, Chan SA (2001) Quantitative determination of sulfonamide in meat by liquid chromatographyelectrospray-mass spectrometry. Talanta 55:1127-1139

Gallego IE (2012) Desarrollo de inmunoensayos para antibióticos en microplaca y en disco compacto aplicados a la determinación multiresiduo de contaminantes. Tesis de doctorado. Departamento de Química, Universidad politécnica de Valencia, España

García J, Pico Y, Font G (2005) Determinación de residuos de quinolonas en alimentos de origen animal mediante electroforesis capilar espectrometría de masas. Revista de toxicología 22:77-88 
García J, Font G, Pico Y (2007) Simultaneous determination of different classes of antibiotics in fish and livestock by CE-MS. Electrophoresis 28:4180-4191

Gentili A, Perret D, Marchese S, Sergy M, Olmi C, Curini R (2004) Accelerated Solvent Extraction and Confirmatory Analysis of Sulfonamide Residues in Raw Meat and Infant Foods by Liquid Chromatography Electrospray Tandem Mass Spectrometry. Journal of Agricultural and Food Chemistry 52:4614-4624

Gentili A, PerretD, MarcheseS (2005)Liquid chromatographytandem mass spectrometry for performing confirmatory analysis of veterinary drugs in animal-food products. Trends in analytical Chemsitry 24:704-733 doi:10.1016/j. trac.2005.02.007

Gehring TA, Rushing LG, Thompson HC (1997) Determination of sulfonamides in edible salmon tissue by liquid chromatography with postcolumn derivatization and fluorescence detection. Journal of $A O A C$ International 80(4)751-755

Gimeno E (2001) El uso responsable de los antimicrobianos como moduladores de crecimiento. Trabajo comunicado a la Academia Nacional de Agronomía y Veterinaria de la República de Argentina pp 1-30

Gratacós M (2007) Desarrollo de métodos rápidos para el análisis de residuos de producción animal. Tesis de Doctorado. Departamento de Química, Universidad de Girona, España

Gros M, Rodríguez MS, Barceló D (2012) Fast and comprehensive multi-residue analysis of a broad range of human and veterinary pharmaceuticals and some of their metabolites in surface and treated waters by ultrahigh-performance liquid chromatography coupled to quadrupole-linear ion trap tandem mass spectrometry. Journal of Chromatography A 1248:104-121

Guy D, Andre F, forsythia D, Tittlemier S (2007) Multiresidue determination of quinolone and fluoroquinolone antibiotics in fish and shrimp by liquid chromatography/ tandem mass spectrometry. Journal of $A O A C$ International 90:604-612

Hajee CA, Rhijn VJ, Lasaroms JJ, Keukens HJ, Jong de Jacob (2001) Development and validation of a method for the determination of sub-additive levels of virginiamycin in compound animal feeds by liquid chromatography. Analyst 126:1332-1338

Hassouan M (2006) Desarrollo de una nueva metodología analítica para la determinación de quinolonas en alimentos de origen animal. Tesis de doctorado. Departamento de Química Analítica, Universidad de Granada, España

Hermo MP, Barrón D, Barbosa J (2006) Development of analytical methods for multiresidue determination of quinolonesin pig muscle samples byliquid chromatography with ultraviolet detection, liquid chromatography-mass spectrometry and liquid chromagraphy-tandem mass spectrometry. Journal of Chromatography A 1104:132-139
Hewitt SA, Kearney M, Currie JW, Young PB, Kennedy DG (2002) Screening and confirmatory strategies for the surveillance of anabolic steroid abuse within Northern Ireland. Analytica Chimica Acta 473:99-109

Horie M, Yoshida T, Saito K, Nakazawa H (1998) Rapid screening method for residual veterinary drugs in meat and fish by HPLC. Journal of the Food Hygienic Society of Japan 39:383-389

Huertas JF (2008) Desarrollo de nuevas metodologías para el análisis ambiental, alimentario y clínico mediante FIA, HPLC Y CE con diferentes tipos de detección espectroscópica. Tesis de doctorado. Departamento de Química Analítica, Universidad de Granada, España

Huetos HO (2004) Estudio comparativo y evaluación de diferentes técnicas cromatográficas en el análisis de residuos de corticosteroides en muestras biológicas. Tesis de Doctorado. Facultad de veterinaria, Universidad Complutense de Madrid, España

ICA Instituto Colombiano Agropecuario. Resolución $\mathrm{N}^{\circ}$ 1966 de 1984. Bogotá: ICA

Informe Técnico (2000) Organización Mundial de la Salud Ginebra 1991, evaluación de ciertos residuos de fármacos de uso veterinario en los alimentos

Jin H, Kumar AP, Paik DH, Ha KC, Yoo YJ, Lee Yl (2010) Trace analysis of tetracycline antibiotics in human urine using UPLC-QToF mass spectrometry. Microchemical Journal 94:139-147

Johnston L, Mackay L, Coft M (2002) Determination of quinolones and fluoroquinolones in fish tissue and seafood by high-performance liquid chromatography with electrospray ionization tandem mass spectrometric detection. Journal of chromatography A 982:97-109

Jung BL, Yun HC, Kwang GunL (2007) Development of an analytical protocol for detecting antibiotic residues in various foods. Food Chemistry 105:1726-1731

Kaufmann A, Butcher P, Maden K, Widmer M (2008) Quantitative multiresidue method for about 100 veterinary drugs in different meat matrices by sub $2-\mu \mathrm{m}$ particulate high-performance liquid chromatography coupled to time of flight mass spectrometry. Journal Chromatography A 1194:66-79

Kellmann M, Muenster H, Zomer P, Mol H (2009) Full Scan MS in Comprehensive Qualitative and Quantitative Residue Analysis in Food and Feed Matrices: How Much Resolving Power is Required? Journal of the American Society for Mass Spectrometry 20:1464-1476

Kennedy DG, McCracken RJ, Cannavan A, Hewitt SA (1998) Use of liquid chromatography-mass spectrometry in the analysis of residues of antibiotics in meat and milk. Journal of Chromatography A 812:77-98

Kowalski P, Oledzka I, Lamparczyk H (2003) Capillary electrophoresis in analysis of veterinary drugs. Journal of Pharmacentical and Biomedical Analysis 32:937-947 
Kowalski P (2008) Capillary electrophoretic method for the simultaneous determination of tetracycline residues in fish samples. Journal of Pharmacentical and Biomedical Analisys 47:487-493

Le Bizec B, Pinel G, Antignac JP (2009) Review Options for veterinary drug analysis using mass spectrometry. Journal of Chromatography A 1216:8016-8034

Lindsey ME, Meyer M, Thurman EM (2001) Analysis of Trace Levels of Sulfonamide and Tetracycline Antimicrobials in Groundwater and Surface Water Using Solid-Phase Extraction and Liquid Chromatography/ Mass Spectrometry. Analytical Chemistry 73(19):46404646

Littlefield NA, Gaylor DW, Blackwell BN, Allen RR (1989) Chronic toxicity/carcinogenicity studies of sulphamethazine in $\mathrm{B} 6 \mathrm{C} 3 \mathrm{~F} 1$ mice. Food and Chemical Toxicology 27:455-463

Lozano M, Arias D (2008) Residuos de fármacos en alimentos de origen animal: panorama actual en Colombia. Revista Colombiana de Ciencias Pecuarias 21:121-135

Lu XW, Dang Z, Yang C (2009) Preliminary investigation of chloramphenicol in fish, water and sediment from freshwater aquaculture pond. International Journal of Environmental Science and Technology 6:597-604

Macarov CA, Tong L, Martínez HM, Hermo MP, Chirila E, Wang YX, Barrón D, Barbosa J (2012) Multi residue determination of the penicillins regulated by the European Union, in bovine, porcine and chicken muscle, by LC-MS/MS. Food Chemistry 135:2612-2621

Márquez LD (2008) Residuos químicos en alimentos de origen animal: problemas y desafíos para la inocuidad alimentaria en Colombia. Revista Corpoica, Ciencia y Tecnología Agropecuaria 9:124-135

Maudens KE, Zhang GF, Lambert WE (2004) Quantitative analysis of twelve sulfonamides in honey after acidic hydrolysis by high-performance liquid chromatography with post-column derivatization and fluorescence detection. Journal of Chromatography A 1047:85-92

Maurer HH, Tenberken O, Kratzsch C, Weber AA, Peters FT (2004) Screening for library-assisted identification and fully validated quantification of 22 beta-blockers in blood plasma by liquid chromatography-mass spectrometry with atmospheric pressure chemical ionization. Journal of Chromatography 1058:169-181

Montalvo M, Olivos O, Gilabert S, Rodríguez A. (2004) Análisis del riesgo de los medicamentos veterinarios presentes en los alimentos. Actualidad en Farmacología y Terapéutica 2(3):168-75

Montoya N (2002) Residuos de antibióticos en camarones: límites residuales y detección de fenicoles cenaim informa, boletín informativo $\mathrm{n}^{\circ} 54$
MsGati TA, Nindi MM (2004) Southern and Eastern Africá network for analytical chemist multiresidue determination of sulfonamides in a variety of biological residues by supported liquid membrane with high pressure liquid chromatography-electrospray mass spectrometry detection. Talanta 64:87-100

Nadezhda AS, Andriana RS, Georgi S (2012) Simultaneous determination of nine quinolones in food by liquid chromatography with fluorescence detection. Food analytical Methods 6(3):803-813 doi 10.1007/s12161-0129488-1

Niessen WM (1998) Review: Analysis of antibiotics by liquid chromatography-mass spectrometry. Journal of Chromatography A 812:53-75

Niessen WM (1999) Chromatographic Science Series. Liquid Chromatography-Mass Spectrometry. In: Taylor \& Francis (3ra Ed.), USA, Vol 97

Niessen WM (2003) Progress in liquid chromatographymass spectrometry instrumentation and its impact on high-throughput screening. Journal of Chromatography $A$ 1000:413-436

O’Mahony J, Clarke L, Whelan M, O'Kennedy R, Lehotay S, Danaher M (2013) The use of ultra-high pressure liquid chromatography with tandem mass spectrometric detection in the analysis of agrochemical residues and mycotoxins in food-challenges and applications. Journal of Chromatography A 1292:83-95

Pena AL, Lino CM, Silveira IN (2003) Determination of Tetracycline Antibiotics in Salmon Muscle by Liquid Chromatography Using Post-Column Derivatization with Fluorescence Detection. Journal of $A O A C$ International 86:925-929

Peng X, Tan J, Tang C, Yu Y, Wang Z (2008) Multiresidue determination of fluoroquinolone, sulfonamide, trimethoprim, and chloramphenicol antibiotics in urban waters in China. Environmental Toxicology and Chemistry 27(1):73-79

Petrovic M, Hernando M, Díaz CS, Barcelo D (2005) Liquid chromatography-tandem mass spectrometry for the analysis of pharmaceutical residues in environmental samples: a review. Journal of Chromatography A 1067:1-14

Poucke CV, Keyser de K , Baltusnikiene A, McEvoy JD, Peteghem CV (2003) Liquid chromatographic-tandem mass spectrometric detection of banned antibacterial growth promoters in animal feed. Analytical Chemical Acta 483:99-109

P.T.I.N.S. (1990) Protocolo de Tratamiento del Instituto Nacional de Saude

Puente ML (2004) Highly sensitive and rapid normalphase chiral screen using high-performance liquid chromatography-atmospheric pressure ionization tandem mass spectrometry (HPLC/MS). Journal of Chromatography 1055:55-62 
Pumarola BA, Rodríguez TA, García RJ Antimicrobianos. In: Elsevier-Masson Microbiología y parasitología médica $2^{a}$ edición, Barcelona, p 127

Ramírez AJ, Moottaleb MA, Bryan WB (2007) Analysis of Pharmaceuticals in Fish Using Liquid Chromatography-Tandem Mass Spectrometry. Analytical Chemistry 79:3155-3163

Reglamento (CEE) n 2377/90, del Consejo de Europa, de 26 de junio, por el que se establece un procedimiento comunitario de fijación de límites máximos de residuos de medicamentos veterinarios en los alimentos de origen animal. DOCE $\mathrm{n}^{\circ} \mathrm{L} 224$ de 18 de agosto de 1990, pp 1-8

Reig RM, Toldrá F (2008) Veterinary drug residues in meat: Concerns and rapid methods for detection. Meat Science 78:60-67

Reig RM (2010) Desarrollo de métodos rápidos de detección de residuos medicamentosos en animales de granja. Tesis de doctorado. Departamento de tecnología de alimentos, Universidad Politécnica de Valencia, España

Rodríguez AM, Gurny R, Veuthey JL, Guillarme D (2013) Coupling ultra-high-pressure liquid chromatography with mass spectrometry: Constraints and possible applications. Journal of Chromatography A 1292:2-18 doi: 10.1016/j.chroma.2012.09.061

Romero GR, López MJ, Gomez EM, Garrido FA, Martínez VJ (2007) Simultaneous determination of selected veterinary antibiotics in gilthead sea bream (Sparus Aurata) by liquid chromatographymass spectrometry. Journal of Chromatography B 857:142148

Romero GR, Fernández MJ, Plazas BP, Garrido A, Martinez VJ (2007) Empleo de la espectrometría de masas como herramienta para la determinación de tóxicos en alimentos: hacia la seguridad alimentaria. Revista Española de salud pública 81:461-474

Sarmah AK, Meyer MT, Boxall AB (2006) A global perspective on the use, sales, exposure pathways, occurrence, fate and effects of veterinary antibiotics (VAs) in the environment. Chemosphere 65:725-759

Sawaya WN, Lone K, Saeed T, Husain A, KhalafawiS (1998) Application of an enzyme-linked immunosorbent assay for screening of sheep urine and animal tissue for the androgenic steroid trenbolone acetate in the State of Kuwait. Food additives \& Contaminants 15(2):151-156

Simeonidou EJ, Botsoglou NA, Psomas IE, Fletouris DJ (1996) Liquid Chromatographic Analysis of Multiple Sulfonamide Residues in Chicken Muscle Using PreColumn Derivatization and Fluorescence Detection. Journal of Liquid Chromatography \& Related Technologies 19(14):2349-2363 doi: 10.1080/10826079608017161
Smallidge RL, Albert K (2000) Determination of sulfamethazine in swine and cattle feed by reversed-phase liquid chromatography with post-column derivatization: collaborative study. Journal of $A O A C$ International 83(2):260-268

Sorensen Lk, Hansen H, Snor L (1999) Determination of Amoxicillin in Trout by Liquid Chromatography with UV Detection after Derivatization. Journal of $A O A C$ International 82:1345-1352

Stolker AA, Brinkman UA (2005) Analytical strategies for residue analysis of veterinary drugs and growthpromoting agents in food-producing animals a review. Journal of Chromatography A 1067:15-53

Stolker AA, Zuidema T, Nielen MW (2007) Residue analysis of veterinary drugs and growth-promoting agents. Trends in Analitical Chemistry 26:967-979

Takeda Nobuyuki, Akiyama Yumi (1991) Pre-column derivatization of sulfa drugs with fluorescamine and high-performance liquid chromatographic determination at their residual levels in meat and meat products. Journal of Chromatography A 558:175-180

Tarbin JA, Clarke p, Shearer G (1999) Screening of sulphonamides in egg using gas chromatography-massselective detection and liquid chromatography-mass spectrometry. Journal of Chromatography B 729:127-138

Thevis M, Opfermann G, Schanzer W (2003) Liquid chromatography/electrospray ionization tandem mass spectrometric screening and confirmation methods for $\beta 2$-agonists in human or equine urine. Journal of Mass Spectrometry 38:1197-1206

Toldrá F, Reig M (2006) Methods for rapid detection of chemical and veterinary drug residues in animal foods. Trends in Food Science y Technology 17:482-489

Tsai CE, Kondo F (1995) Liquid chromatographic determination of fluorescent derivatives of six sulfonamides in bovine serum and milk. Journal of $A O A C$ International 78(3):674-678

Turnipseed SB, Roybal JE, Andersen WC, Kuck LR (2005) Analysis of avermectin and moxidectin residues in milk by liquid chromatography-tandem mass spectrometry using an atmospheric pressure chemical ionization/ atmospheric pressure photoionization source. Analytica Cbimica Acta 529:159-165

Uberos FJ (2005) Utilidad del cloramfenicol tras 60 años de uso. Sociedad española de pediatría extrahospitalaría y atención primaria. Granada, 14 de julio de 2005 http:/ / www.sepeap. org/archivos/revisiones/infeccioso/cloramfenicol.htm

Verdon E, Couedor P, Roudaut B, Sanders P (2005) Multiresidue Method for simultaneous determination of ten quinolone antibacterial residues in multimatrix/ multispecies animal tissues by liquid chromatography with fluorescence detection: single laboratory validation study. Journal of $A O A C$ international 88:1179-1192 
Volmer DA, Mansoori B, Locke SJ (1997) Study of 4-Quinolone Antibiotics in Biological Samples by Short-Column Liquid Chromatography Coupled with Electrospray Ionization Tandem Mass Spectrometry. Analytical Chemistry 69:4143-4155

Yorke JC, Froc P (2000) Quantitation of nine quinolones in chicken tissues by High-performance liquid chromatography with fluorescence detection. Journal of Chromatography A 882:63-77

Técnicas analíticas contemporáneas para la identificación de residuos de sulfonamidas, quinolonas y cloranfenicol

Resumen. El uso excesivo de fármacos en la industria veterinaria genera bioacumulación en órganos, tejidos, músculos y grasa animal. Dependiendo de la concentración, estos residuos llegan al hombre vía cadena alimentaria. La normatividad para dicha problemática en algunos países, no es suficiente, por eso es fundamental establecer normas estipuladas por la unión europea, sentando bases para su vigilancia y control a nivel nacional. La seguridad alimentaria está relacionada con el uso de fármacos y sus residuos, ejemplo de ellos, son las sulfonamidas, quinolonas y cloranfenicol, que se han encontrado en diferentes animales de abasto.

En esta revisión, se incluyen técnicas analíticas empleadas para la identificación de los residuos generados por fármacos, enfatizando en aquellas tecnologías de reciente desarrollo y que son herramientas fundamentales para el control de esta problemática. La cromatografía líquida combinada con la espectrometría de masas y sus diferentes sistemas de interfaces, son las tecnologías más recomendadas para la detección de este tipo de residuos en diferentes matrices alimentarias.

Palabras clave: Bioacumulación; promotores de crecimiento; fármacos, control de residuos; seguridad alimentaria; cromatografía líquida; espectrometría de masas.
Yoshida H, Yamazaki J, Ozawa S, Mizukoshi T, Miyano H (2009) Advantage of LC-MS metabolomics methodology targeting hydrophilic compounds in the studies of fermented food samples. Journal of Agricultural and Food Chemistry 57:1119-1126

Técnicas analíticas contemporâneas para a identificação de resíduos de sulfonamidas, quinolonas e cloranfenicol

Resumo. O uso excessivo de drogas na indústria veterinária gera bio-acumulação em órgãos, tecidos, músculos e gordura animal. Dependendo da concentração, estes resíduos chegam ao homem através da cadeia alimentar. Os regulamentos para este problema em alguns países não é suficiente, por isso é essencial estabelecer normas estipuladas pela União Europeia, que determina as bases para o monitoramento e controle a nível nacional. A segurança alimentar está relacionada com o uso de fármacos e seus resíduos, por exemplo, sulfonamidas, quinolonas e cloranfenicol os quais foram encontrados em diferentes animais para abate.

Nesta revisão, incluem-se técnicas analíticas utilizadas para a identificação dos resíduos gerados pelos fármacos, enfatizando as tecnologias recentemente desenvolvidas as quais são ferramentas essenciais para controlar este problema. Cromatografia líquida combinada com a espectrometria de massa e seus vários sistemas de interfaces são as tecnologias mais recomendadas para a deteção deste tipo de resíduos em diversas matrizes alimentares.

Palavras-chave: Bio-acumulação; pomotores de crescimento; fármacos; controle de residuos; segurança alimentar; cromatografia líquida; espectrometria de massa. 